\title{
Arterial thromboembolism in a young woman with occult dilated cardiomyopathy
}

\author{
Alicia Topoll ${ }^{1}$, Jordan Owens ${ }^{1}$, Jorge Cheirif ${ }^{2}$, J. Mark Pool $^{3}$, Mark Feldman*1 \\ ${ }^{1}$ Texas Health Presbyterian Hospital of Dallas, Dallas, TX, USA \\ ${ }^{2}$ Presbyterian Heart and Vascular Group, Texas Health Physicians Group, Dallas, TX, USA \\ ${ }^{3}$ Cardiac, Vascular, and Thoracic Surgical Associates, Texas Health Physicians Group, Dallas, TX, USA
}

Received: April 27, 2016

DOI: $10.5430 /$ crim.v3n $3 p 12$
Accepted: May 26, 2016

Online Published: June 5, 2016

\begin{abstract}
An acute dilated cardiomyopathy may present with vague symptoms including fatigue and malaise, which may delay the diagnosis until signs and symptoms of systolic heart failure develop. Left ventricular thrombus and arterial thromboembolism are rare complications of acute dilated cardiomyopathy. We present a case of a young Caucasian woman presenting with acute leg ischemia secondary to femoral artery thromboembolism associated with a previously undiagnosed acute dilated cardiomyopathy with severe systolic heart failure and a large left ventricular thrombus. Her prothrombotic state was refractory to heparin therapy and surgical vascular intervention. She eventually required leg amputation for recurrent limb ischemia with gangrene and thrombus extraction from the left ventricle. Risk factors for her prothrombotic state included the acute, dilated cardiomyopathy, use of a hormonal contraceptive agent, obesity, smoking, and a heterozygous Factor II (Prothrombin) G20110A mutation.
\end{abstract}

Key Words: Dilated cardiomyopathy, Left ventricular thrombus, Arterial thromboembolism, Myocarditis, Prothrombin gene mutation, Prothrombotic state

\section{INTRODUCTION}

Left ventricular thrombus formation, with its potential for cerebral embolization with ischemia or stoke or for peripheral embolization to a limb with ischemia or gangrene (or to another organ) is a known complication of acute myocardial infarction. We present an unusual case of a large left ventricular thrombus with embolization to the leg with ischemia and gangrene in a young, previously healthy woman with an unrecognized acute dilated cardiomyopathy, presumably caused by viral myocarditis.

\section{CASE REPORT}

A 30-year-old previously healthy Caucasian woman presented to an outside facility's emergency department with a one hour history of acute right leg numbness, paresthesia of her right toes, cramping and severe pain of the right foot, and leg weakness. It was noted that her right lower extremity was pale and purplish. While in their emergency department, she became acutely hypoxemic (85\% oxygen saturation on an $\mathrm{FiO}_{2}$ of $55 \%$ using a non-rebreather mask), with a metabolic acidosis. She was placed on bi-level positive airway pressure with improvement of her hypoxemia and acidemia. After a lower extremity Doppler ultrasonography showed extensive clot in the right lower extremity arterial system with little to no distal flow and after a CT angiogram of her chest showed a crescentic left ventricular thrombus with mild cardiomegaly and interstitial pulmonary infiltrates concerning for acute respiratory distress syndrome, pulmonary edema, or pneumonia,

*Correspondence: Mark Feldman, MD; Email: MarkFeldman@ @ texashealth.org; Address: 8200 Walnut Hill Ln, Dallas, TX 75231, USA. 
she was transferred to our facility on a heparin infusion for a higher level of care.

Six days earlier she had transient left upper extremity and left facial numbness. She had been evaluated at that time by an outside facility's emergency department with CT of her head and neck, which were negative for any abnormality. An outpatient appointment with a neurologist had been scheduled for further evaluation. She denied chest pain, shortness of breath, a recent viral illness or other symptoms.

Her past medical history was significant for obesity, attention deficit hyperactivity disorder (treated with lisdexamfetamine) and depression (treated with citalopram). Her only other medication was an oral contraceptive pill, a combination of ethinyl estradiol and drospirenone. She had no history of thrombophilia. She had a 4-pack-year history of cigarette use and reported using e-cigarettes currently. She drank one glass of wine per day and denied illicit drug use. She worked for an insurance company and was able to perform all of her activities of daily living prior to this episode. She had no family history of premature heart disease, cardiomyopathy, or thrombophilia.

Upon transfer to our facility, she was obese, with a body mass index of $35 \mathrm{~kg} / \mathrm{m}^{2}$. Her blood pressure was $129 / 81$ $\mathrm{mmHg}$, temperature was $98.3^{\circ} \mathrm{F}$, heart rate was regular at 135 beats per minute, and respiratory rate was 22 breaths per minute. Cardiovascular examination demonstrated a laterally displaced PMI with no lift, heave or thrill, a I/VI holosystolic murmur auscultated best at the left lower sternal border, and an S3 gallop. She had no jugular venous distention. Diffuse rales were present. Her abdominal examination was normal. Right leg cyanosis with mottling was present in addition to marked ankle weakness with plantar flexion and dorsal flexion. Deep tendon reflexes were symmetrical. Dorsalis pedis, posterior tibial and popliteal pulses could not be appreciated in the right leg. The right femoral pulse was also unable to be palpated, but was present using Doppler. The right leg was cold to the thigh.

Laboratory studies are summarized in Table 1. The white blood cell count and serum troponin I, BNP, and CRP were quite elevated. Her urine drug screen was positive only for amphetamines. Anti-nuclear antibodies and anti-cardiolipin antibodies were negative. She was heterozygous for the Factor II (Prothrombin) G20210A mutation. Blood and urine cultures had no growth. A respiratory viral plus PCR panel was negative for 12 respiratory pathogens and was indeterminate (abnormal) for an adenovirus. Heterophile antibody testing for Epstein-Barr virus was negative. Arterial Doppler studies confirmed a right femoral artery thrombus. CT of the chest showed a large, crescentic thrombus in the left ventricle (see Figure 1). An electrocardiogram showed a marked sinus tachycardia, left anterior fascicular block, incomplete right bundle branch block, and lack of anterior $\mathrm{R}$ wave progression (see Figure 2). A transthoracic echocardiogram demonstrated a $7 \mathrm{~cm} \times 4 \mathrm{~cm}$ highly mobile pedunculated thrombus in the left ventricle (see Figure 3 ) and a globallydepressed left ventricular ejection fraction of only $10 \%$, with mild right ventricular dysfunction, consistent with dilated cardiomyopathy. Mild mitral regurgitation was also noted on the echocardiogram without other valve abnormality.

Table 1. Laboratory results, on or soon after admission to our facility

\begin{tabular}{|c|c|c|c|}
\hline White blood count & $22.49 \mathrm{k} / \mu \mathrm{l}(\mathrm{H})$ & Arterial blood gas & $\begin{array}{l}\text { BiPap with } \\
\mathrm{FiO}_{2}, 100 \%\end{array}$ \\
\hline Red blood count & $4.58 \mathrm{M} / \mu \mathrm{l}$ & $\mathrm{pH}$ & $7.25(\mathrm{~L})$ \\
\hline Hemoglobin & $13.8 \mathrm{~g} / \mathrm{dl}$ & $\mathrm{pCO}_{2}$ & $41.9 \mathrm{mmHg}$ \\
\hline Hematocrit & $40.7 \%$ & pO2 & $257.7 \mathrm{mmHg}(\mathrm{L})$ \\
\hline Platelet count & $164 \mathrm{k} / \mu \mathrm{l}$ & $\mathrm{HCO}_{3}^{-}$ & $18 \mathrm{mmol} / \mathrm{L}(\mathrm{L})$ \\
\hline Pro time/INR & $15.1 \mathrm{~s}(\mathrm{H}) / 1.2$ & Base Excess & $-8.8 \mathrm{mmol} / \mathrm{L}(\mathrm{L})$ \\
\hline aPTT & $43.9 \mathrm{~s}(\mathrm{H})$ & $\begin{array}{l}\mathrm{O}_{2} \text { saturation } \\
\text { (Calculated) }\end{array}$ & $99.70 \%$ \\
\hline Sodium & $136 \mathrm{mmol} / \mathrm{L}$ & A-a $\mathrm{O}_{2}$ Gradient & $403 \mathrm{mmHg}(\mathrm{H})$ \\
\hline Chloride & $105 \mathrm{mmol} / \mathrm{L}$ & $\mathrm{P} / \mathrm{F}$ arterial ratio & 257.7 (L) \\
\hline Potassium & $3.6 \mathrm{mmol} / \mathrm{L}$ & & \\
\hline Carbon dioxide & $17 \mathrm{mmol} / \mathrm{L}(\mathrm{L})$ & $\begin{array}{l}\text { Cardiolipin } \\
\text { Antibody, IgG }\end{array}$ & 2 \\
\hline BUN & $9 \mathrm{mg} / \mathrm{dl}$ & $\begin{array}{l}\text { Cardiolipin } \\
\text { Antibody, IgM }\end{array}$ & 7 \\
\hline Creatinine & $0.96 \mathrm{mg} / \mathrm{dl}$ & Protein S, functional & $88 \%$ \\
\hline Troponin I & $6.159 \mathrm{ng} / \mathrm{ml}(\mathrm{H})$ & $\begin{array}{l}\text { Antithrombin } \\
\text { III, functional }\end{array}$ & $75 \%(L) *$ \\
\hline Creatine kinase & $275 \mathrm{U} / \mathrm{L}(\mathrm{H})$ & APC Resistance & 3.4 \\
\hline Creatine kinase MB & $12.00 \mathrm{U} / \mathrm{L}(\mathrm{H})$ & $\begin{array}{l}\text { Factor V Leiden } \\
\text { mutation }\end{array}$ & Negative \\
\hline $\mathrm{BNP}$ & $1495 \mathrm{pg} / \mathrm{ml}(\mathrm{H})$ & $\begin{array}{l}\text { Prothrombin } \\
\text { G20210 mutation }\end{array}$ & Heterozygous \\
\hline CRP & 13.9 mg/dl (H) & & \\
\hline
\end{tabular}

Note. (H): higher than reference range; (L): lower than reference range.

*slightly low antithrombin level is probably attributed to the recent acute thrombosis, heparin therapy, or both.

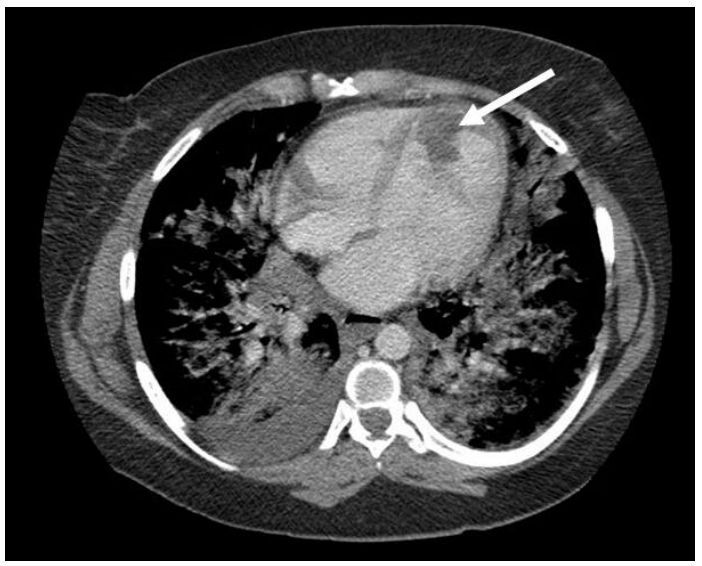

Figure 1. CT scan. Crescentic thrombus (arrow) in the left ventricle with mild cardiomegaly 


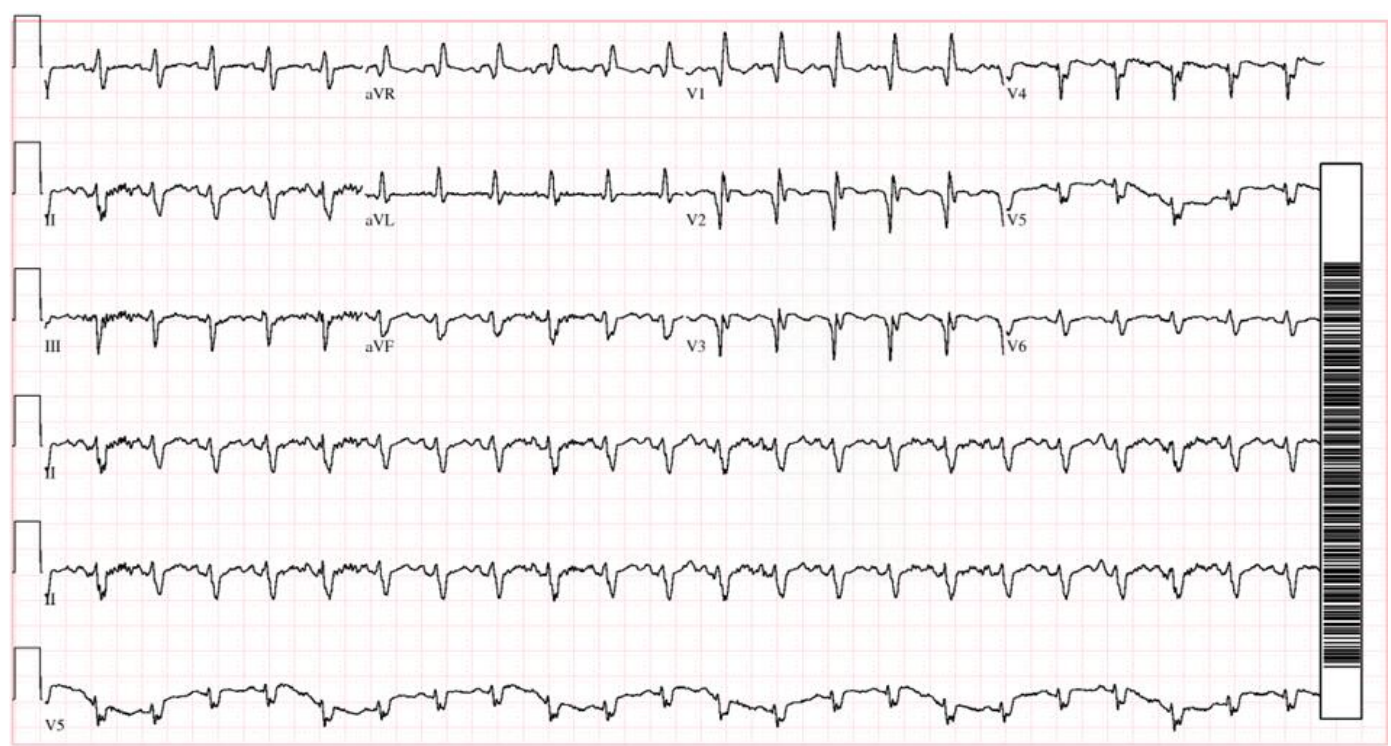

Figure 2. Electrocardiogram. Sinus tachycardia at $136 \mathrm{bpm}$ with a left anterior fascicular block and incomplete right bundle branch block with poor R-wave progression anteriorly

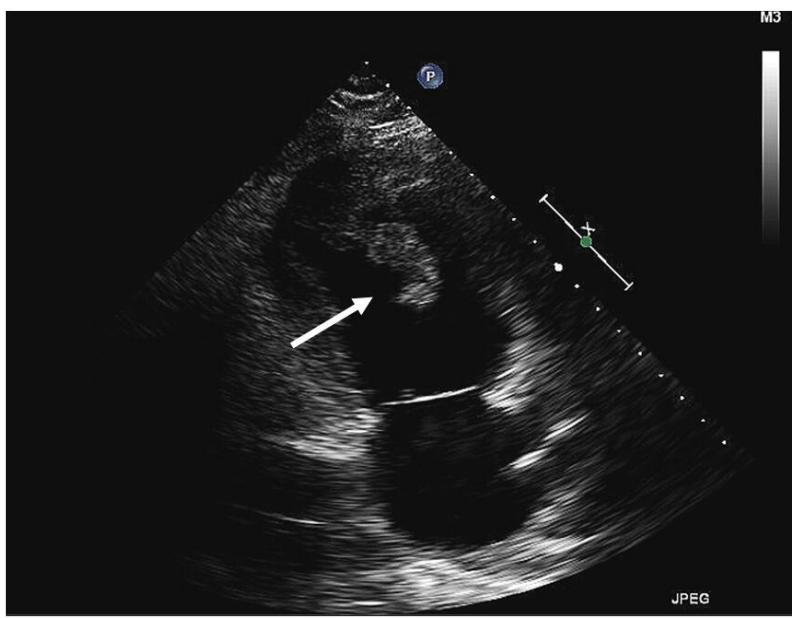

Figure 3. Transthoracic echocardiogram. Large protruding apical thrombus seen in the left ventricle (arrow)

Intravenous unfractionated heparin infusion was continued. Femoral embolectomy was performed soon after transfer to our hospital but rethrombosis of the right profunda femoris, superficial femoral and common femoral arteries occurred which required repeat thrombectomy on hospital day 2 . After this second procedure, she had a palpable popliteal pulse, but no pulse or Doppler signal at the dorsalis pedis or posterior tibial sites. Serum troponin I levels remained elevated, ranging from 2.409 to $2.846 \mathrm{ng} / \mathrm{ml}$ on day 2 (reference range, $<$ $0.028 \mathrm{ng} / \mathrm{ml})$.

Coronary angiography was considered but not performed due to the patient's acute limb ischemia. Because of the large and highly mobile left ventricular thrombus despite therapeutic doses of heparin, the patient was felt to be at high risk for cerebral and further systemic arterial embolization. On hospital day 11 she underwent a two-staged procedure under one anesthetic with right above the knee amputation due to dry gangrene and extraction of thrombus from the left ventricle. The thrombus was removed using a minimally invasive approach with partial upper sternotomy and full cardiopulmonary bypass. Transaortic access to the left ventricle was used in which the aortic valve leaflets were gently retracted out of the way and a thoracoscope inserted to enhance visualization of the left ventricular chamber. She recovered well and went to an acute rehabilitation facility after 23 days. She has remained on warfarin and has not experienced any additional embolic events. Through more than 2 years of follow up, she has regained ambulation and has returned to work. There has been no recurrence of the apical thrombus on multiple follow-up transthoracic echocardiograms. Her most recent echocardiogram while receiving continued medical therapy for her systolic heart failure, performed a little more than 2 years after her original presentation, showed a left ventricular ejection fraction of $35 \%-40 \%$. She still had apical, distal septal, distal anterior and inferior akinesia, with normal left ventricular diastolic function, mild tricuspid regurgitation, and an estimated right ventricular systolic pressure of $37 \mathrm{mmHg}$.

\section{Discussion}

Our patient presented with acute limb ischemia secondary to embolization to the right femoral artery from a large left ventricular thrombus. She was then quickly diagnosed with likely occult myocarditis complicated by a dilated cardiomyopathy with severe systolic heart failure. She also had a 
herald, presumably embolic, transient cerebral ischemic attack 6 days earlier. Her acute limb ischemia was refractory to embolectomy and heparin therapy and she ultimately required a leg amputation for gangrene and removal of the large mobile left ventricular thrombus via a transaortic approach.

Myocarditis presents as a wide spectrum of symptoms including malaise, fatigue, weakness, and symptoms of decompensated heart failure. ${ }^{[1-10]}$ Laboratory examination may show leukocytosis, an elevated C-reactive protein level (or erythrocyte sedimentation rate) and an elevated serum troponin level, all present in our patient. Viral infections are common causes of acute myocarditis in Europe and North America. Coxsackie B, an enterovirus, causes between $25 \%-40 \%$ of all cases. ${ }^{[9]}$ However, other viruses including adenovirus, parvovirus B19, Epstein-Barr virus, human herpes virus-6, and hepatitis $C$ virus are recognized causes of myocarditis. ${ }^{[2,7-10]}$ Due to low clinical yield and lack of specific treatment, viral serologic tests are not routinely recommended for evaluation of myocarditis ${ }^{[2,6]}$ and were not performed in our patient. A PCR on suctioned sputum in our patient was abnormal (indeterminate) for an adenovirus, raising the possibility of adenovirus myocarditis. A diagnosis of myocarditis may be confirmed by an endomyocardial biopsy (EMB) and cardiac MRI may assist in the diagnosis of myocarditis. ${ }^{[2,7]}$ EMB is performed infrequently since myocarditis is a clinical diagnosis and EMB has a low sensitivity and there is a lack of specific therapy. EMB involves obtaining a specimen from the intraventricular septum, but recent studies have indicated that myocarditis often starts on the lateral free wall of the left ventricle. EMB of the septum thereby may not show histologic evidence of myocarditis even though the patient may meet criteria for myocarditis by clinical and radiographic criteria. ${ }^{[2,6,7]}$ We did not biopsy the left ventricle at the time of upper sternotomy and transaortic removal of the left ventricular thrombus because there is often sampling error and biopsy results would not change her planned overall management and because we did not want to expose the patient to further biopsy-associated risks.

The history of amphetamine use for attention deficit hyperactivity disorder raises the question of this drug's role in her development of this illness. However, at the prescribed dose in our patient, lisdexamfetamine should not have resulted in cardiomyopathy. ${ }^{[11,12]}$

Patients with dilated cardiomyopathy are at increased risk of left ventricular thrombus formation due to marked stagnation of blood flow in the left ventricle. ${ }^{[13,14]}$ Pedunculated and mobile thrombi confer the highest risk of systemic embolization. ${ }^{[1,2]}$ If ventricular thrombosis is diagnosed, anticoagulation with heparin and then warfarin is indicated. ${ }^{[2]}$ Lee et al. studied a variety of therapies that included warfarin, antiplatelet agents, and surgical thrombus removal and there were no significant differences in morbidity, although fewer thromboembolic events were found in the surgical thrombus removal group. ${ }^{[13]}$

Besides having the acute dilated cardiomyopathy with stagnant blood flow in her left ventricle, additional risk factors for developing the mobile left ventricular thrombus included oral contraceptive use, obesity, recent tobacco use, and, perhaps most importantly, a heterozygous G20210A mutation in the Factor II (Prothrombin) gene. Most individuals with this G20210A mutation are Caucasian and are heterozygotes for this variant, ${ }^{[15]}$ although homozygosity has been reported in a small number of cases. ${ }^{[16]}$ The prevalence of the G20210A mutation in Caucasian populations is approximately $2 \%$. Transmission is thought to be autosomal dominant. The mutation is in the 3' untranslated region of the gene and is considered to be a gain-of-function mutation. As a result, heterozygotes have modestly increased plasma prothrombin levels, and rarer homozygotes have even higher levels. Most studies of patients with this mutation have found an increased risk of venous thromboembolism, with a slight risk of arterial thrombosis, particularly in young individuals with stroke. ${ }^{[17,18]}$ Use of oral contraceptive agents may pose additive risks in patients with thrombophilias, and therefore should be avoided. However, most of the studies on the interactions between hormonal contraceptives and thrombophilias included patients with other mutations (Factor V Leiden) or deficiencies (protein $\mathrm{C}$, protein $\mathrm{S}$, antithrombin). ${ }^{[17,18]}$ Likewise, her obesity and smoking habits may have further increased the risk of thrombosis.

Due to the large mobile clot on a thin stalk, the transient ischemic attack 6 days prior to her hospitalization, and recurrent femoral arterial thromboembolism on heparin therapy there was significant concern for risk of thromboembolic stroke. Our patient was a young and otherwise healthy female and thus we opted for surgical intervention to remove the large mobile clot and decrease her risk of further thromboembolic events. We did not use fibrinolytic therapy to try to dissolve the clots in her femoral arterial system or her left ventricle because we believed the risks of bleeding and stroke in this postoperative patient with a recent cerebral transient cerebral ischemic attack exceeded the possible benefits.

Our patient underwent uncomplicated above the knee amputation of the right leg and apical thrombus removal. The minimally invasive approach for removal of the left ventricular thrombus allowed a more straightforward rehabilitation, because her lower sternum was intact and her upper body could be used more reliably in compensating for her lower 
extremity amputation. In addition, the transaortic approach allowed the left ventricle muscle to remain intact; a more traditional approach with incision through the left ventricular myocardium to remove the thrombus would have likely led to worsening left ventricular function.

EMB was not performed because there is often sampling er- ror and biopsy results would not change her planned overall management and also to avoid risks associated with biopsy of the left ventricle. The patient did well after left ventricular thrombus removal and has been on warfarin and has had no further left ventricular clot and has not experienced further thromboembolic phenomenon over the past 2 years of follow up.

\section{REFERENCES}

[1] Richardson P, McKenna W, Bristow M, et al. Report of the 1995 World Health Organization/International Society and Federation of Cardiology Task Force on the definition and classification of cardiomyopathies. Circulation. 1996; 93: 841. PMid:8598070 http: //dx.doi.org/10.1161/01.CIR.93.5.841

[2] Caforio AL, Pankuweit S, Arbustini E, et al. Current state of knowledge on aetiology, diagnosis, management, and therapy of myocarditis: a position statement of the European Society of Cardiology Working Group on Myocardial and Pericardial Diseases. Eur Hear J 2013.

[3] Nindl V, Maier R, Ratering D. Cooperation of Th1 and Th17 cells determines transition from autoimmune myocarditis to dilated cardiomyopathy. Eur J Immunol. 2012; 42(9): 2311-21. PMid:22730043 http://dx.doi.org/10.1002/eji.201142209

[4] Noutsias M, Rohde M, Göldner K. Expression of functional T-cell markers and T-cell receptor Vbeta repertoire in endomyocardial biopsies from patients presenting with acute myocarditis and dilated cardiomyopathy. Eur J Heart Fail. 2011; 13(6): 611-8. PMid:21422001 http://dx.doi.org/10.1093/eurjhf/hfr014

[5] Fairweather D, Cooper LT Jr, Blauwet LA. Sex and gender differences in myocarditis and dilated cardiomyopathy. Curr Probl Cardiol 2013; 38(1): 7-46. PMid:23158412 http://dx.doi.org/10.10 16/j.cpcardiol.2012.07.003

[6] Kindermann I, Barth C, Mahfoud F, et al. Update on myocarditis. J Am Coll Cardiol. 2012; 59: 779-792. PMid:22361396 http: //dx.doi.org/10.1016/j.jacc.2011.09.074

[7] Mahrholdt H, Goedecke C, Wagner A, et al. Cardiovascular magnetic resonance assessment of human myocarditis: A comparison to histology and molecular pathology. Circulation. 2004; 109(10): 1250-8. PMid:14993139 http://dx .doi.org/10.1161/01.CIR. 0000118493.13323 .81

[8] Lazzerini PE, Capecchi PL, Laghi-Pasini F. Statins as a new therapeutic perspective in myocarditis and postmyocarditis dilated cardiomyopathy: editorial to "Pitavastatin regulates helper T-cell differentiation and ameliorates autoimmune myocarditis in mice". Cardiovasc Drugs Ther. 2013; 27(5): 365-9. PMid:23832693 http: //dx.doi.org/10.1007/s10557-013-6475-8

[9] Gaaloul I, Riabi S, Harrath R, et al. Coxsackievirus B detection in cases of myocarditis, myopericarditis, pericarditis and dilated car- diomyopathy in hospitalized patients. Mol Med Rep. 2014; 10(6): 2811-8. http://dx.doi.org/10.3892/mmr. 2014. 2578

[10] Xie Y, Li M, Wang X, et al. In vivo delivery of adenoviral vector containing interleukin-17 receptor a reduces cardiac remodeling and improves myocardial function in viral myocarditis leading to dilated cardiomyopathy. PLoS One. 2013; 8(8): e72158. PMid:23977238 http://dx.doi.org/10.1371/journal.pone.0072158

[11] Albertson TE, Derlet RW, Van Hoozen BE. Methamphetamine and the expanding complications of amphetamines. Western Journal of Medicine. 1999; 170(4): 214-219.

[12] Marks DH. Cardiomyopathy due to ingestion of Adderall. Am J Ther. 2008; 15(3): 287-9. PMid:18496266 http://dx . doi.org/10.10 97/MJT . Ob013e3180ed6291

[13] Lee JM, Park JJ, Jung HW, et al. Left ventricular thrombus and subsequent thromboembolism, comparison of anticoagulation, surgical removal, and antiplatelet agents. J Atheroscler Thromb. 2013; 20(1): 73-93. PMid:22986555 http://dx.doi.org/10.5551/jat. 135 40

[14] Zaidi SM, Al-Khuwaitir TS, Wani BA, et al. Resolution of a large left ventricular thrombus with anticoagulation alone. Saudi Med J. 2005; 26(9): 1445-8. PMid:16155667

[15] Poort SR, Rosendaal FR, Reitsma PH, et al. A common genetic variation in the 3'-untranslated region of the prothrombin gene is associated with elvelated plasma prothrombin levels and an increased risk in venous thrombosis. Blood. 1996; 88: 3698-3703. PMid:8916933

[16] Girolami A, Scarano L, Tormeme D, et al. Homozygous patients with the $20210 \mathrm{G}$ to A prothrombin polymorphism remain often asymptomatic in spite of the presence of associated risk factors. Clin Appl Thromb Hemost. 2001; 7: 122-125. PMid:11292189

[17] Vanderbroucke JP, Koster T, Briët E, et al. Increased risk of venous thrombosis in oral-contraceptive users who are carriers of Factor V Leiden mutation. Lancet. 1994; 344: 1453-1457. http: //dx.doi.org/10.1016/S0140-6736(94)90286-0

[18] Van Vlijmen EF, Brouwer JL, Veeger NJ, et al. Oral contraceptives and the absolute risk of venous thromboembolism in women with single or multiple thrombophilic defects: results from a retrospective family cohort study. Arch Int Med. 2007; 167: 282-289. PMid:17296885 http://dx.doi.org/10.1001/archinte.167. 3.282 